\title{
Mental health literacy and attitudes in a Swedish community sample - Investigating the role of personal experience of mental health care
}

\author{
Karin M Dahlberg*1,2, Margda Waern ${ }^{3}$ and Bo Runeson ${ }^{1}$
}

Address: ${ }^{1}$ Department of Clinical Neuroscience, Section for Psychiatry St. Göran, Karolinska Institute, Stockholm, Sweden, ${ }^{2}$ Department of Psychiatry, Central Hospital, Skövde, Sweden and ${ }^{3}$ Department of Psychiatry and Neurochemistry, Sahlgrenska Academy at Göteborg University, Göteborg, Sweden

Email: Karin M Dahlberg* - karin.dahlberg@vgregion.se; Margda Waern - margda.waern@neuro.gu.se; Bo Runeson - bo.runeson@ki.se

* Corresponding author

Published: 9 January 2008

BMC Public Health 2008, 8:8 doi:10.1 I86/147/-2458-8-8

This article is available from: http://www.biomedcentral.com/I47I-2458/8/8

(c) 2008 Dahlberg et al; licensee BioMed Central Ltd.

This is an Open Access article distributed under the terms of the Creative Commons Attribution License (http://creativecommons.org/licenses/by/2.0), which permits unrestricted use, distribution, and reproduction in any medium, provided the original work is properly cited.
Received: 30 April 2007

Accepted: 9 January 2008

\begin{abstract}
Background: Mental ill health is a common condition in the general population, yet only about half of those with a mental disorder have treatment contact. Personal experience may affect attitudes, which in turn influence the help-seeking process. This study investigated differences in mental health literacy and attitudes among mentally healthy persons and in persons with symptoms of mental illness with and without treatment contact.
\end{abstract}

Method: A postal screening questionnaire was sent to a random sample of the general population aged 20-64 in the county of Skaraborg, Sweden in order to ascertain mental health status and history of treatment contact; 3538 responded (49\%). Face-to-face interviews were carried out in random sub samples of mentally healthy persons $(n=128)$ and in mentally ill persons with $(n=125)$ and without $(n=105)$ mental health care contact. Mental health literacy and attitudes to treatment were assessed using questions based on a vignette depicting a person with depression. Past month mental disorder was diagnosed according to the Schedule for Clinical Assessment in Neuropsychiatry (SCAN).

Results: Two thirds failed to recognize depression in a vignette; recognition was equally poor in mentally healthy persons and in persons with symptoms of mental illness with and without treatment contact. In response to an open-ended question concerning appropriate interventions, one third suggested counselling and only one percent proposed antidepressant treatment. Again, proportions were similar in all groups. Persons with a history of mental health contact more often suggested that a GP would provide the best form of help. When presented with a list of possible interventions, those with a history of mental health contact were more positive to medical interventions such as antidepressants, hypnotics, and inpatient psychiatric treatment. When asked about the prognosis for the condition described in the vignette, persons with treatment contact were less likely to believe in full recovery without intervention; mentally ill without treatment contact were more optimistic.

Conclusion: Mental health literacy, specially concerning attitudes towards interventions is associated with personal history of mental health care. 


\section{Background}

Mental disorders are common in the general population, with a lifetime prevalence of about $40-50 \%$ [1-3]. The high prevalence for a common mental disorder such as depression is an obvious public health problem involving both the suffering of individuals and their families and significant costs for society [4-6]. Unmet need for mental health care is a widespread problem [7]. Only half of those with a diagnosis of mental or addictive disorders receive any treatment from the mental health system [810].

Help-seeking behaviour is complex. Rates of treatment contact differ among mental disorders. Among high-prevalence disorders, panic disorder and mood disorders have the highest rates of treatment contact, while alcohol related disorders have the lowest rates $[8,11,12]$. Women, middle-aged people, whites and those with a higher level of education have higher rates of treatment contact $[8,13$ 15].

An important part of help seeking is recognition; does the subject recognize his/her problem as a mental disorder? A review on the issue shows that a substantial proportion of the lay public cannot correctly recognize mental disorders [16]. Lay people often attribute mental illness to psychosocial stress rather than a medical disorder [17-20], which probably affects the demand for treatment. Beliefs about the helpfulness of interventions for mental disorders differ in professionals and lay persons [21]. National awareness campaigns aimed at improving public understanding of depression and its treatment have been implemented in countries such as the United Kingdom and Australia $[22,23]$. Evaluations of the campaigns have shown positive changes in attitudes towards depression and its treatment $[22,23]$, most notably concerning counselling and medication but also about the value of help-seeking in general [22]. It also appears to have improved the recognition of depression and the impact of this illness [24]. Recent research from Australia, however, reveals that there has yet not been any significant improvement in the prevalence of depression [25]. While no such population education strategy has been implemented in Sweden, there has been a marked increase in antidepressant prescription rates over the past fifteen years. Antidepressants are currently prescribed to an estimated 5\% of the population [26]. This suggests that depression and anxiety disorders, for which these drugs are indicated, are now more often recognized and treated by Swedish physicians. In light of this, it would be of interest to study mental health literacy and attitudes towards treatment in a Swedish population.

The aim of the present study was to examine if there was a relationship between a personal history of mental health care and mental health literacy. Age and gender differ- ences were also examined. The ability to recognize a common mental disorder (e.g. depression) and attitudes towards interventions and prognosis were studied.

\section{Method \\ Material \\ Stage I}

A population-based survey was performed during March 2000-March 2003. In the first stage a postal screening questionnaire was distributed and responding to the questionnaire was considered as informed consent. The primary survey population consisted of all Swedish residents aged 20-64 in the former County of Skaraborg. For the purpose of the study a sample of 7500 subjects was randomly selected from the general population register; 254 could not be reached. The response rate for the postal questionnaire was $49 \%$ (3 538/7 246). In the primary survey population 125893 people were between 20-64 years old, $29.0 \%$ aged $20-34,35.6 \%$ aged $35-49$ and $35.2 \%$ aged 50-64. Forty-nine per cent were women. Among the responders fifty-five per cent were women, $26.6 \%$ aged $20-34,34.5 \%$ aged $35-49$ and $38.9 \%$ aged $50-64$.

\section{Screening questionnaire}

The purpose of the screening was to ascertain mental health status and history of treatment contact for mental health problems. The questionnaire included demographic data, a self-report instrument rating symptoms of mental disorder, and questions about health care contact. The self-report instrument has previously been used in a population study of mental disorders in Stockholm, Sweden $[27,28]$.

A respondent was defined as screening positive for symptoms of mental ill health if at least one of the following screening criteria were met:

* $\geq$ Six symptoms of anxiety and/or panic attacks with anticipatory fear of future attacks. The questions were based on Sheehan Patient-Rated (Panic) Scale [29].

$*$ One symptom of avoidance of agoraphobic or social phobic situations due to fear or anxiety. The symptoms were assessed using questions from Mark and Mathews brief standard rating for phobic patients [30]. Three questions on agoraphobia including avoidance of transport vehicles, shops or cinemas, and open places. Avoidance of social situations due to fear or anxiety was investigated concerning the following circumstances: avoiding eating, drinking or writing in public, avoiding being in the centre of attention, avoiding being with other people due to a high level of self-criticism. One question concerning avoidance of other situations was included. 
$* \geq$ One obsessive compulsive symptom during last 30 days and suffering due to this [31]. Three screening questions recommended by the Swedish Psychiatric Association and the Swedish Institute for Health Service Development were included. These concerned obsessional washing, checking, and intrusive unpleasant thoughts. A question measuring severity of social impairment was added, in accordance with DSM-IV criteria.

$*$ Five symptoms of depression lasting more than two weeks causing disability according a slightly modified Major Depression Inventory (MDI) (4 point-scale [32] instead of the usual 6 point-scale) [33,34]. A question about significant distress during the last 14 days, caused by the symptoms, was included.

* Presence of suicidal thoughts some of the time or more often during the last two weeks, according to the MDI.

* Alcohol Use Disorder Identification Test score (AUDIT) $\geq 11$ [35].

* Any use of illicit drugs during last year.

* $\geq$ One symptom of social disability due to psychological problems measured according to WHO's brief Disability Assessment Schedule (WHO-DAS-S) [36,37].

* Self-report of an ongoing life-crisis, depression, "burnout", or other mental disorder (according to a checklist).

* Current psychoactive drug prescription. (All respondents who had indicated present use of medication were asked to list their medications including doses. These lists were manually checked for psychoactive drugs).

The respondents were asked whether they had contacted health care for sleep disturbance, personal problem or mental health problems. In case of a positive answer, the respondents were asked to indicate present (last three months) and/or former contact from a checklist. The sources of care that could be indicated included specialised mental health care (psychiatric outpatient clinic of a psychiatric hospital; independent psychiatrist, psychologist or psychotherapist) and primary care (general practitioner, company physician, and non-psychiatric independent physicians). All respondents with health care contact during the past three months, as well as all those with a history of contact with specialised mental health care, were coded as having contact for a mental health problem. Subjects who were currently prescribed psychoactive drug were also considered to have contact with health care for mental health problems.
645 persons $(18.2 \%)$ had mental ill health as defined above. Ten percent of the total sample $(\mathrm{N}=353)$ had health care contact for mental health problems (group I: cases with contact). An additional 292 persons (8.3\%) fulfilled above criteria but had no relevant health care contact (group II: cases without contact). Among the cases with contact, $37 \%$ reported depressive symptoms, $18 \%$ had symptoms of any anxiety syndrome (but no depressive symptoms) and 7\% had harmful alcohol use (but no depressive symptoms, no anxiety symptoms). The remaining had either indicated disability due to psychological problems, ongoing mental disorder or current psychoactive drug prescription. The corresponding numbers for cases without contact is $36 \%$ with depressive symptoms, $20 \%$ with anxiety symptoms and $24 \%$ with harmful alcohol use. Respondents who did not meet the above stated criteria for "caseness" ( $n=2893)$ were classified as mentally healthy (group III: mentally healthy).

\section{Stage II}

A random sample from each of the three groups was invited to participate in a face-to-face interview. Among cases 'with contact' we approached 141 people; 125 $(89 \%)$ agreed to participate in an interview. The corresponding figures for 'cases without contact' were 105/160 $(66 \%)$. Of the mentally healthy, 252 persons were randomly chosen for an interview; 128 interviews were conducted (51\%). Fifty per cent of the interviews took place in the homes of the respondents and the remainder were conducted at the research office.

\section{Interview}

The mean time between the screening questionnaire and the interview was 4 months (range 1-7 months). The interview began with a vignette developed by Jorm and colleagues [38] designed to determine mental health literacy. The vignette depicted a diagnostically unlabelled case with major depressive disorder. Either a female (Anna) or a male (Magnus) version was presented, depending on the sex of the respondent.

"Anna is 30 years old. She has been feeling unusually sad and miserable for the last few weeks. Even though she is tired all the time, she has trouble sleeping almost every night. Anna doesn't feel like eating and has lost weight. She can't keep her mind on her work and puts off making decisions. Even day-to-day tasks seem too much for her. This has come to the attention of Anna's boss who is concerned about her lowered productivity. "

After being presented with the vignette, respondents were questioned about what was wrong and how the person could be helped. Recognition was examined using an open-ended question: "What, if anything, do you think is wrong with Anna?" If multiple responses were given, only the label closest to the correct diagnosis (depression) was 
registered. Optimal form of help was assessed by asking the respondents how Anna/Magnus best could be helped.

After responding to these open-ended questions, participants were shown a list of different interventions (professionals and other potential helpers, medications and a variety of other treatments) and asked to rate each intervention as helpful, harmful or neither. Respondents were then asked about the prognosis (full recovery, full recovery with risk of relapse, partial recovery, partial recovery with risk of relapse, no improvement, or progression) were the person to receive the preferred intervention. Finally, they were asked to assess prognosis in a similar manner, were the person described in the vignette to receive no treatment at all.

Following the administration of the vignette based questions, the interviewer used the Schedule of Clinical Assessment in Neuropsychiatry (SCAN) version 2.1 PART 1, chapter $1-8$ and $11[39,40]$ to generate past month diagnoses in accordance with DSM-IV [41].

The instrument including the vignette and the questions were translated to Swedish by the investigators and checked and edited by colleagues. The Ethical Committee of Karolinska Institute approved the study.

\section{Statistical analysis}

Cross tabulation with $\mathrm{Chi}^{-}{ }^{2}$ test was used to evaluate differences among sex, age groups, and interview groups. Multiple logistic regression analyses were carried out with correct recognition as dependent variable and sex, age group, level of education and interview group (mentally healthy/cases with contact/cases without contact) as covariates. Age was trichotimized (20-34, 35-49 and 50-64 years) with the middle group as the reference. Three educational levels were identified $(0-9,10-12$ and $>12$ years), with the middle group as the reference group. Statistical data management, descriptive analyses and analyses of the data were carried out using Statistical Package for Social Sciences (SPSS 12.0 for Windows) [42].

\section{Results}

The age and gender distributions in the three interview groups are shown in Table 1. The proportion of young people was notably larger among cases without contact with mental health care. The difference in age and gender distribution among the groups was taken into consideration in further analyses.

\section{Recognition of depression}

Less than one third of the respondents recognized depression (Figure 1). Twenty per cent indicated that the problem described in the vignette was due to stress and another $20 \%$ considered it a day-to-day problem. The responses to the open-ended question "What is wrong" did not differ significantly between the three interview groups. Twenty-three respondents fulfilled criteria for present major depressive episode in accordance with SCAN and $39 \%$ of these recognized that the vignette depicted depression (n.s. compared to the rest of the respondents).

More women than men correctly recognized depression, $36 \%$ versus $21 \%(\mathrm{p}=0.002)$. A larger proportion of the youngest age group (20-34) recognized depression, $42 \%$ compared to $24 \%(\mathrm{p}=0.001)$ in the two older age groups. Among the respondents, 59 were women aged 20-34, of these $52 \%$ recognized depression, which was better than in females in the older age groups, $31 \%(\mathrm{p}=0.003)$, and also better than in males in the young age group, $28 \%$ (p $=0.013)$. The multiple regression model was in line with the above results. Female sex (OR 2.07, p = 0.006), younger age (OR 1.99, $\mathrm{p}=0.028)$, and higher education (OR 1.85, $\mathrm{p}=0.025$ ) predicted recognition. History of mental health care did not predict recognition in the regression model.

\section{Best form of help}

About one third of the participants in each interview group responded that the best form of help would be to seek counselling (Table 2) and counselling was the most common response to that open-ended question. While one fifth of those with mental health contact suggested

Table I: Participants in the face-to-face interview. Demographic characteristics in cases with and without mental health care contact and in mentally healthy.

\begin{tabular}{|c|c|c|c|c|c|}
\hline & A Cases with contact $N=125$ & B Cases without contact $N=105$ & C Mentally healthy $N=128$ & Total $N=358$ & $\mathrm{p}$-value \\
\hline Male & $48(38 \%)$ & $48(46 \%)$ & $52(41 \%)$ & 148 (4I\%) & n.s. \\
\hline Female & $77(62 \%)$ & $57(54 \%)$ & $76(59 \%)$ & $210(59 \%)$ & n.s. \\
\hline 20-34 years & 24 (19\%) & $46(44 \%)$ & $29(23 \%)$ & $99(28 \%)$ & $\begin{array}{l}\mathrm{B}>\mathrm{A}, \mathrm{P}<0.001 \\
\mathrm{~B}>\mathrm{C}, \mathrm{P}=0.001\end{array}$ \\
\hline $35-49$ years & $42(34 \%)$ & $30(28 \%)$ & $42(33 \%)$ & II 4 (32\%) & n.s. \\
\hline $50-64$ years & $59(47 \%)$ & $29(28 \%)$ & $57(44 \%)$ & 145 (40\%) & $\begin{array}{c}A>B, P=0.02 \\
C>B, P=0.008\end{array}$ \\
\hline
\end{tabular}




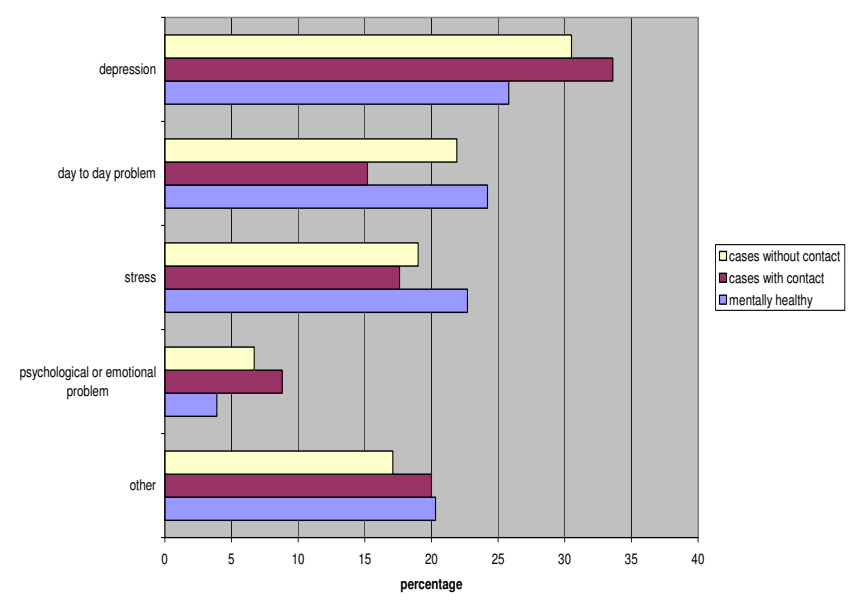

Figure I

Perceived problem in response to vignette depicting depression. Open ended responses shown for subgroups with and without contact for mental health problems, and for mentally healthy.

that the person in the vignette would be best helped by a GP, proportions suggesting a GP were significantly lower in the other two interview groups. Persons with mental health contact were less likely to respond that family or close friend would constitute the best form of help. Very few of the respondents considered a psychiatrist the best source of help; there was no difference among interview groups. Medication was seldom considered the best form of help. Work-related interventions were preferred by $15 \%$ of the total group. Again, there were no differences among groups.

When results for the total group were examined separately by sex, women were more likely than men, $16 \%$ versus
$5 \%(\mathrm{p}=0.003)$ to suggest contact with a GP as the best form of help.

\section{Helpfulness of listed interventions}

The top five interventions rated as helpful were relaxation techniques, talking to family or close friends, physical activity, psychotherapy, and consulting a psychologist. The ratings for each intervention are presented by subgroup in Table 3. Cases without mental health contact more often rated family or close friends as helpful compared to cases with such contact. Three quarters of those with mental health contact rated antidepressants as helpful, a proportion larger than that in the other two interview groups (50\% in each group). Sixty-three persons were on antidepressants at the time of the interview and $90 \%$ of these rated antidepressants as helpful compared to $51 \%$ among all others ( $p=0.000)$. One fifth of the respondents thought that antidepressants could be harmful, 31\% among cases without contact and 26\% among mentally healthy, compared to only $8 \%$ among cases with mental health care contact $(\mathrm{p}=0.000)$. No significant differences could be shown for sex or age on this topic. Thirty-nine respondents had some form of ongoing psychosocial intervention and/or formal psychotherapy at the time of the interview (data retrieved from the SCAN interview), and of these $92 \%$ rated psychotherapy as helpful for the person in the vignette, compared to $74 \%$ ( $\mathrm{p}=$ 0.000 ) among the rest of the respondents.

Table 3 shows further that one fifth of the cases with mental health contact rated admission to a psychiatric ward as helpful; this proportion was significantly larger than that for cases without contact. Almost sixty percent (57.8\%) rated admission to a psychiatric ward as harmful; there were no significant differences among groups. The youngest age group was most negative, $71 \%$ compared to $53 \%$ for the rest of the respondents $(p=0.001)$.

Table 2: Best form of help - responses to open-ended question

\begin{tabular}{|c|c|c|c|c|}
\hline & $\begin{array}{l}\text { A Cases with contact } \\
\qquad N=125\end{array}$ & $\begin{array}{l}\text { B Cases without contact } \\
\qquad N=105\end{array}$ & $\begin{array}{l}\text { C Mentally healthy } \\
\qquad N=128\end{array}$ & $\mathrm{p}$-value \\
\hline & (\%) & (\%) & (\%) & \\
\hline Counselling & 34.4 & 34.3 & 35.9 & n.s. \\
\hline Help from family or close friend & 11.2 & 24.8 & 24.2 & $\begin{array}{l}B>A, P=0.007 \\
C>A, P=0.007\end{array}$ \\
\hline See a doctor (GP) & 20.8 & 9.5 & 6.3 & $\begin{array}{l}A>B, P=0.019 \\
A>C, P=0.001\end{array}$ \\
\hline Work related intervention & 15.2 & 13.3 & 17.2 & n.s. \\
\hline $\begin{array}{l}\text { Anna/Magnus must first recognise } \\
\text { the problem }\end{array}$ & 7.2 & 5.7 & 3.9 & n.s. \\
\hline See a psychiatrist & 2.4 & 1.9 & 0.8 & n.s \\
\hline Take medication & 4.0 & 1.0 & 0 & n.s. \\
\hline Something else & 3.2 & 6.7 & 8.6 & n.s. \\
\hline Don't know & 3.2 & 1.0 & 3.1 & n.s. \\
\hline
\end{tabular}


Table 3: Percentage of respondents who rated listed interventions as helpful.

\begin{tabular}{|c|c|c|c|c|}
\hline Type of intervention & $\begin{array}{l}\text { A Cases with contact } \\
\qquad N=125\end{array}$ & $\begin{array}{l}\text { B Cases without contact } \\
\qquad N=105\end{array}$ & $\begin{array}{l}\text { C Mentally healthy } \\
N=128\end{array}$ & $\mathrm{p}$-value \\
\hline People who could help & (\%) & (\%) & (\%) & \\
\hline GP/family doctor & 60.0 & 49.5 & 52.3 & n.s. \\
\hline Psychiatrist & 68.8 & 61.0 & 63.3 & n.s. \\
\hline Psychologist & 77.6 & 73.3 & 75.0 & n.s. \\
\hline Close family/friends & 76.8 & 90.5 & 84.4 & $\begin{array}{l}B>A \\
P=0.006\end{array}$ \\
\hline Naturopath/herbalist & 33.9 & 33.3 & 41.4 & n.s. \\
\hline Clergy & 32.0 & 42.9 & 41.4 & n.s. \\
\hline $\begin{array}{l}\text { Anna/Magnus tries to deal with } \\
\text { problems on her/his own }\end{array}$ & 63.2 & 66.7 & 64.8 & n.s. \\
\hline \multicolumn{5}{|l|}{ Medications } \\
\hline Vitamins and minerals & 52.8 & 54.3 & 53.9 & n.s. \\
\hline Pain relievers & 5.6 & 4.8 & 3.9 & n.s. \\
\hline Antibiotics & 0.8 & 2.9 & 3.9 & n.s. \\
\hline Antidepressants & $74.4 \%$ & 47.6 & 50.8 & $\begin{array}{l}A>B, P<0.001 \\
A>C, P<0.001\end{array}$ \\
\hline Sleeping pills & 56.8 & 38.1 & 39.8 & $\begin{array}{l}A>B, P=0.005 \\
A>C ; P=0.007\end{array}$ \\
\hline Tranquilisers & 31.5 & 24.8 & 24.2 & n.s \\
\hline \multicolumn{5}{|l|}{ Activities/therapies } \\
\hline Becoming more physically active & 77.6 & 84.8 & 81.3 & n.s. \\
\hline Self-help books & 72.0 & 58.1 & 58.6 & n.s. \\
\hline Getting out and about more & 58.4 & 68.6 & 64.1 & n.s. \\
\hline $\begin{array}{l}\text { Relaxation, stress management, } \\
\text { meditation, yoga }\end{array}$ & 89.6 & 88.6 & 94.5 & n.s. \\
\hline Cutting out alcohol all together & 66.1 & 61.9 & 65.6 & n.s. \\
\hline Psychotherapy & 80.8 & 73.3 & 72.7 & n.s. \\
\hline Hypnosis & 19.2 & 16.2 & 9.4 & n.s. \\
\hline $\begin{array}{l}\text { Admission to a psychiatric ward of a } \\
\text { hospital }\end{array}$ & 20.0 & 6.7 & 14.1 & $A>B, p=0.004$ \\
\hline Electroconvulsive therapy $(\mathrm{ECT})$ & 7.2 & 1.9 & 3.9 & n.s. \\
\hline Having an occasional drink to relax & 4.8 & 2.9 & 5.5 & n.s. \\
\hline $\begin{array}{l}\text { A special diet or avoiding certain } \\
\text { food }\end{array}$ & 24.0 & 27.6 & 19.7 & n.s. \\
\hline
\end{tabular}

Electroconvulsive Therapy (ECT) was rated as harmful by $71 \%$, cases without contact rated ECT as harmful in $80 \%$ compared to $62 \%$ among cases with contact $(\mathrm{p}=0.006)$. The youngest age group (20-34) was most negative towards ECT, $82 \%$ compared to $66 \%$ for the rest of the respondents $(p=0.002)$. An occasional drink was the intervention most commonly rated as harmful. At the time of the interview 20 persons fulfilled SCAN criteria for alcohol abuse or alcohol dependence, of these $65 \%$ rated an occasional drink as harmful compared to $87 \%$ among the rest of the respondents $(\mathrm{p}=0.004)$.

\section{Ratings of prognosis}

The participants were asked to give their opinion about the prognosis with and without the intervention they had indicated as most appropriate in response to the openended question. Eighty-four per cent believed that there would be full recovery or full recovery with risk of relapse with appropriate help (Table 4). No significant differences could be detected among interview groups. In the alternative without intervention, $16 \%$ believed in full recovery or full recovery with risk of relapse. These replies were much more common among cases without contact compared to cases with contact $(23 \%$ versus $8 \%, \mathrm{p}=0.002)$. One third (31\%) believed that there would be progression of symptoms without appropriate support; there were no differences among groups.

\section{Discussion}

Only about a third of those with a personal history of treatment for mental illness recognized depression, a proportion similar to that observed among persons with no such history. However, attitudes concerning psychological and medical interventions for a person with depressive symptoms were more positive among those with a personal history. Due to the cross-sectional design of our 
Table 4: Anticipated prognosis with and without treatment

\begin{tabular}{|c|c|c|c|c|c|c|c|c|}
\hline & \multicolumn{4}{|c|}{ Prognosis with preferred intervention } & \multicolumn{4}{|c|}{ Prognosis without any form of intervention } \\
\hline & $\begin{array}{c}\text { A Cases with } \\
\text { contact } N=125\end{array}$ & $\begin{array}{c}\text { B Cases without } \\
\text { contact } \mathrm{N}= \\
105\end{array}$ & $\begin{array}{c}\text { C Mentally } \\
\text { healthy } N=128\end{array}$ & P-value & $\begin{array}{c}\text { A Cases with } \\
\text { contact } N=125\end{array}$ & $\begin{array}{l}\text { B Cases without } \\
\text { contact } N=105\end{array}$ & $\begin{array}{c}\text { C Mentally } \\
\text { healthy } N=128\end{array}$ & P-value \\
\hline & $(\%)$ & $(\%)$ & $(\%)$ & & $\%$ & $\%$ & $\%$ & \\
\hline Full recovery & 26.9 & 27.6 & 32.0 & n.s. & 0.8 & 3.8 & 3.9 & n.s. \\
\hline $\begin{array}{l}\text { Full recovery } \\
\text { with risk of } \\
\text { relapse }\end{array}$ & 56.8 & 55.2 & 52.3 & n.s. & 7.2 & 19.0 & 14.1 & $\begin{array}{l}B>A, \\
P=0.007\end{array}$ \\
\hline Partial recovery & 4.0 & 8.6 & 3.9 & n.s. & 4.0 & 3.8 & 10.9 & n.s. \\
\hline $\begin{array}{l}\text { Partial recovery } \\
\text { with risk of } \\
\text { relapse }\end{array}$ & 12.8 & 8.6 & 10.9 & n.s. & 33.6 & 30.5 & 32.0 & n.s. \\
\hline $\begin{array}{l}\text { No } \\
\text { improvement }\end{array}$ & 0 & 0 & 0 & n.s. & 15.2 & 10.5 & 10.2 & n.s. \\
\hline Progression & 0 & 0 & 0 & n.s. & 36.8 & 31.4 & 25.8 & n.s. \\
\hline
\end{tabular}

study, we cannot assume that these more positive attitudes are a direct result of the treatment experience. It is probable that persons with positive attitudes towards mental health care would be more likely to seek help in the first place. Before results are discussed further, some comments concerning methodology are warranted.

\section{Strengths and limitations}

Strengths of the study include a study design with a welldefined population. It is advantageous to carry out such a study in a country like Sweden where every resident has a unique personal identification number. This facilitates sampling and respondents may be more representative of the underlying population than those who are selected by random telephoning and household sampling. While there was considerable non-participation at the questionnaire stage, our response rate is higher than in some other studies in the field $[22,24]$. Still, it is probable that persons with psychiatric symptoms and negative attitudes to help-seeking are overrepresented among those who did not respond to the postal questionnaire.

The method of postal questionnaire was chosen with the specific purpose of reaching also a non-clinical group, namely persons with symptoms of mental disorder but no treatment contact. Most of the subjects classified as cases had an active clinical picture. As expected there were somewhat fewer subjects with active symptoms among the cases with contact, probably due to successful treatment. It is notable that even though cases without contact had not sought help for their symptoms, as many as two out of three of these opted to participate in an interview about their mental health and personal problems, when an opportunity was offered.
Due to the skewness in participation rate at the second stage, significant differences among the groups may have been missed. As expected, cases with mental health care contact had the highest participation rate. It was also fairly easy to recruit cases without mental health care contact. However, it was more difficult to motivate mentally healthy to participate in the interview. One might assume that those who are sceptical to mental health care and what it offers are less inclined to participate in an investigation like this. Another limitation is that the study did not have the power to detect group differences in attitudes to interventions that were chosen by a small number of persons. For example, while the proportion of cases with contact who were positive about ECT was thrice that of the group without contact, the difference in proportions was not significant.

The study did not focus on particular diagnostic entity, but rather on mental illness within a much broader context. This is a weakness, when it comes to comparability with other research, but could also be seen as strength as those sampled with this approach mirror the mental health status in the community.

\section{Recognition}

Less than one third correctly recognized that the vignette depicted a depression. This study was set in a country without a national depression awareness campaign, and it is thus not surprising that many respondents $(60 \%)$ described the problem within the broader context of mental illness (including depression, mental illness, stress and emotional problems) rather than specifically identifying depression. Our findings can be compared to results from a country such as Australia, where public recognition of depression increased from 39\% in 1997 to $67 \%$ in 2003-2004 [43]. Efforts have been made on many levels 
in the Australian society to enhance public knowledge about the ubiquity of mental disorders, particularly depression, but it is still difficult to attribute the improvement of mental health literacy about depression to any one factor [44].

Recognition of a depression from a vignette did not differ among our three interview groups. Neither was recognition influenced by the fact that the individual actually had a current episode of major depression. It has previously been shown by Goldney and co-workers [45], that those with a major depression were no more likely than others to recognize a depression. One explanation for this might be cognitive impairment due to depression.

Female sex, young age and a higher degree of education were associated with recognition. Greater mental health literacy has been shown in younger persons than in older persons in Australia [46]. In our study, young women were the group with the best mental health literacy; more than fifty per cent recognized depression. Consequently, males and less educated groups have difficulties in recognizing depression which may prevent them from seeking help from the mental health care system. This may result in unmet needs, which has recently been pointed out as a motive for strategies that target these groups [47].

\section{Interventions}

In response to the open-ended question regarding the best form of treatment, one third of the participants suggested counselling and there was no difference among groups. A large majority of the respondents favoured psychotherapy. This is in line with other reports based on case vignettes [16]. A review of preferences among depressed patients in primary care reveals that a majority prefer counselling or psychotherapy [48].

Significantly more respondents among cases with contact were in favour of consulting a GP, compared to both cases without contact and mentally healthy. Only $13 \%$ of the total group recommended contact with a GP, a proportion considerably smaller than reported from Australia, where half of the respondents indicated that the person in the vignette should contact their GP [44]. While this may be due to different attitudes towards GPs, it may also reflect differences in how primary care is structured in Australia and Sweden. It is not always easy to get an appointment with a GP in Sweden, and there is often a lack of physician continuity which might make persons less willing to seek help for mental health problems. The proportion of respondents in the current study who indicated that workrelated interventions would provide the best help was similar to the proportion that suggested contact with a GP. During the interview many respondents made note of the boss' concern regarding lower productivity. Stressful work environments resulting in sick leave due to "burn-out" have been a recent focus in the Swedish mass media, and this might in part explain the finding that as many as 15 percent considered that the best form of help would be a work related intervention.

Cases with contact were less positive towards the lay support system; this was the case both in the open-ended and in the forced responses. It is possible that cases with history of mental health contact had previously elicited help from family and friends and had found that insufficient. This could have played a role in their decision to seek treatment. Cases without contact preferred the lay support system. Previous research from Germany shows that the public opinion favours the lay support system for depression [49]. In Australia, however, only one fifth suggested lay support $[43,45]$. As mentioned above, the most common suggestion was the GP, which might reflect the strong role of the family doctor.

Concerning pharmacological interventions, such as antidepressants, cases with contact were more positive than both cases without contact and mentally healthy. This was even more pronounced in the subgroup that was presently using antidepressants; nine out of ten rated this medication as helpful. In light of previous research, it was somewhat unexpected that half of those without contact rated antidepressants as helpful. Other research shows that most lay people have negative views of antidepressants $[16,50]$ and less than one third of general population or depressed primary care samples are positive about treatment with antidepressants [48]. In the present study $20 \%$ rated antidepressants as harmful, a figure similar to that reported from Australia [44]. Reasons for public scepticism include worry about side effects and the belief that antidepressants may cause dependency [48]. Also, it has been shown that psychotropic drugs provoke fear of losing control to a larger extent than drugs indicated for physical illness [51]. A question may be to what extent the individual's experience may affect treatment preferences? Jorm and co-workers showed that people who had sought help for depression were more likely to believe in medical interventions [52].

\section{Outcome with and without professional help}

As in other research [16] our participants perceive the course of depression more optimistically with appropriate treatment than in the absence of treatment. Studies from Europe, Asia and Australia report that only about 5\% of the population believe in full recovery for depression without help $[53,54]$. In our study one fourth of the cases without contact believed in full recovery without intervention. Is this optimism based on own experience of recovery without treatment or is it due to an underestimation of the problem? 


\section{Conclusion}

While a personal history of mental health care was not associated with better recognition of depression, attitudes toward psychological and medical interventions were clearly more positive in this group. It is also worthwhile to note that counselling was the favoured intervention in all groups. Resources for psychotherapeutic treatments have been rather scarce in many parts of Sweden, but in recent years short term psychotherapy has become increasingly available in primary care settings. One focus of future research could be to investigate attitudes before and after more individualized treatment.

\section{Competing interests}

The author(s) declare that they have no competing interests.

\section{Authors' contributions}

KD contributed to the conception and design of the study, acquisition of data, analysis and interpretation of results, and drafting/completion of the paper. MW contributed to the interpretation of results, and drafting/completion of the paper. BR contributed to the conception and design of the study, interpretation of results, and drafting/completion of the paper. All authors have read and approved the final manuscript.

\section{Acknowledgements}

Thanks for generous funding go to the Vardal Foundation - for Health Care Sciences and Allergy Research, the Skaraborg Institute for Research and Development and the Dahréns Foundation, the Research Fund at Skaraborg Hospital, and the R \& D Centre Skaraborg Primary Care. Special thanks go to Håkan Andersson, Ing-Britt Eriksson and Eva Marie Hellsvik for their valuable help with the interviews.

\section{References}

I. Kringlen E, Torgersen S, Cramer V: A Norwegian psychiatric epidemiological study. Am J Psychiatry 2001, 158:1091-1098.

2. Kessler RC, Berglund P, Demler O, Jin R, Merikangas KR, Walters EE: Lifetime prevalence and age-of-onset distributions of DSMIV disorders in the National Comorbidity Survey Replication. Arch Gen Psychiatry 2005, 62:593-602.

3. Bijl RV, Ravelli A, van Zessen G: Prevalence of psychiatric disorder in the general population: results of The Netherlands Mental Health Survey and Incidence Study (NEMESIS). Soc Psychiatry Psychiatr Epidemiol 1998, 33:587-595.

4. Murray CJ, Lopez AD: Evidence-based health policy--lessons from the Global Burden of Disease Study. Science 1996, 274:740-743.

5. Cuijpers P, Smit F, Oostenbrink J, de Graaf R, Ten Have M, Beekman $A$ : Economic costs of minor depression: a population-based study. Acta Psychiatr Scand 2007, II 5:229-236.

6. Sobocki P, Lekander I, Borgstrom F, Strom O, Runeson B: The economic burden of depression in Sweden from 1997 to 2005. Eur Psychiatry 2007, 22:146-152.

7. Alonso J, Codony M, Kovess V, Angermeyer MC, Katz SJ, Haro JM, De Girolamo G, De Graaf R, Demyttenaere K, Vilagut G, Almansa J, Lepine JP, Brugha TS: Population level of unmet need for mental healthcare in Europe. BrJ Psychiatry 2007, 190:299-306.

8. Bijl RV, Ravelli A: Psychiatric morbidity, service use, and need for care in the general population: results of The Netherlands Mental Health Survey and Incidence Study. Am J Public Health 2000, 90:602-607.
9. Lehtinen V, Joukamaa M, Jyrkinen E, Lahtela K, Raitasalo R, Maatela J, Aromaa A: Need for mental health services of the adult population in Finland: results from the Mini Finland Health Survey. Acta Psychiatr Scand 1990, 81:426-431.

10. Regier DA, Narrow WE, Rae DS, Manderscheid RW, Locke BZ, Goodwin FK: The de facto US mental and addictive disorders service system. Epidemiologic catchment area prospective I-year prevalence rates of disorders and services. Arch Gen Psychiatry 1993, 50:85-94

II. Kessler RC, Olfson M, Berglund PA: Patterns and predictors of treatment contact after first onset of psychiatric disorders. Am J Psychiatry 1998, 155:62-69.

12. Mojtabai R, Olfson M, Mechanic D: Perceived need and helpseeking in adults with mood, anxiety, or substance use disorders. Arch Gen Psychiatry 2002, 59:77-84.

13. Alegria M, Bijl RV, Lin E, Walters EE, Kessler RC: Income differences in persons seeking outpatient treatment for mental disorders: a comparison of the United States with Ontario and The Netherlands. Arch Gen Psychiatry 2000, 57:383-391.

14. Gallo JJ, Marino S, Ford D, Anthony JC: Filters on the pathway to mental health care, II. Sociodemographic factors. Psychol Med 1995, 25: I I49-II 60.

15. Rabinowitz J, Gross R, Feldman D: Correlates of a perceived need for mental health assistance and differences between those who do and do not seek help. Soc Psychiatry Psychiatr Epidemiol 1999, 34:|4|-|46.

16. Angermeyer MC, Dietrich S: Public beliefs about and attitudes towards people with mental illness: a review of population studies. Acta Psychiatr Scand 2006, I I 3:163-179.

17. McKeon P: Public attitudes to depression: a national survey. Irish Journal of Psychological Medicine 1991, 8:1|6-121.

18. Dietrich S, Beck M, Bujantugs B, Kenzine D, Matschinger H, Angermeyer MC: The relationship between public causal beliefs and social distance toward mentally ill people. Aust N Z J Psychiatry 2004, 38:348-54; $\quad$ discussion

19. Hugo CJ, Boshoff DE, Traut A, Zungu-Dirwayi N, Stein DJ: Community attitudes toward and knowledge of mental illness in South Africa. Soc Psychiatry Psychiatr Epidemiol 2003, 38:71 5-7I 9.

20. Matschinger $\mathrm{H}$, Angermeyer MC: Lay beliefs about the causes of mental disorders: a new methodological approach. Soc Psychiatry Psychiatr Epidemiol 1996, 3 1:309-315.

21. Jorm AF, Korten AE, Jacomb PA, Rodgers B, Pollitt P, Christensen H, Henderson S: Helpfulness of interventions for mental disorders: beliefs of health professionals compared with the general public. Br J Psychiatry 1997, I 7 I:233-237.

22. Jorm AF, Christensen $H$, Griffiths KM: The impact of beyondblue: the national depression initiative on the Australian public's recognition of depression and beliefs about treatments. Aust N Z J Psychiatry 2005, 39:248-254.

23. Paykel ES, Hart D, Priest RG: Changes in public attitudes to depression during the Defeat Depression Campaign. BrJPsychiatry 1998, 173:519-522.

24. Highet NJ, Luscombe GM, Davenport TA, Burns JM, Hickie IB: Positive relationships between public awareness activity and recognition of the impacts of depression in Australia. Aust N Z J Psychiatry 2006, 40:55-58.

25. Goldney RD, Fisher LJ, Grande ED, Taylor AW, Hawthorne G: Have education and publicity about depression made a difference? Comparison of prevalence, service use and excess costs in South Australia: 1998 and 2004. Aust N Z J Psychiatry 2007, 4I:38-53.

26. Schmidt I, Bergmark E, Lieberman-Ram H, Fastbom J: Antidepressants in mental illhealth. Antidepressiva vid psykisk ohälsa.(in Swedish). Stockholm, Socialstyrelsen; 2006:96.

27. Lundberg I, Damstrom Thakker K, Hallstrom T, Forsell Y: Determinants of non-participation, and the effects of non-participation on potential cause-effect relationships, in the PART study on mental disorders. Soc Psychiatry Psychiatr Epidemiol 2005, 40:475-483.

28. Dahlberg K, Forsell Y, Damstrom-Thakker K, Runeson B: Mental health problems and healthcare contacts in an urban and a rural area. Comparisons of two Swedish counties. Nord J Psychiatry 2007, 61:40-46.

29. Sheehan DV: The anxiety disease. New York, Charles Scribners Sons; 1983:pp 124-129. 
30. Marks IM, Mathews AM: Brief standard self-rating for phobic patients. Behav Res Ther 1979, 17:263-267.

31. Swedish Psychiatric Association: Anxiety syndromes - clinical guidelines for assessment and treatment (in Swedish). Stockholm, Spris förlag; 1997:27.

32. Dahlin M, Joneborg N, Runeson B: Stress and depression among medical students: a cross-sectional study. Med Educ 2005, 39:594-604

33. Bech P, Wermut L: Applicability of the Major Depression Inventory in patients with Parkinson's disease. Nord J Psychiatry 1998, 52:305-309.

34. Bech P, Rasmussen NA, Olsen LR, Noerholm V, Abildgaard W: The sensitivity and specificity of the Major Depression Inventory, using the Present State Examination as the index of diagnostic validity. I Affect Disord 200I, 66:159-164.

35. Saunders JB, Aasland OG, Babor TF, de la Fuente JR, Grant M: Development of the Alcohol Use Disorders Identification Test (AUDIT): WHO Collaborative Project on Early Detection of Persons with Harmful Alcohol Consumption--II. Addiction |993, 88:79|-804.

36. Janca A, Kastrup M, Katschnig H, Lopez-Ibor JJ Jr., Mezzich JE, Sartorius N: The World Health Organization Short Disability Assessment Schedule (WHO DAS-S): a tool for the assessment of difficulties in selected areas of functioning of patients with mental disorders. Soc Psychiatry Psychiatr Epidemiol 1996, 31:349-354.

37. Ormel J, Vonkorff M, Oldehinkel AJ, Simon G, Tiemens BG, Ustun TB: Onset of disability in depressed and non-depressed primary care patients. Psychol Med 1999, 29:847-853.

38. Jorm AF, Korten AE, Jacomb PA, Rodgers B, Pollitt P: Beliefs about the helpfulness of interventions for mental disorders: a comparison of general practitioners, psychiatrists and clinical psychologists. Aust N ZJ Psychiatry 1997, 31:844-85I.

39. Aboraya A, Tien A, Stevenson J, Crosby K: Schedules for Clinical Assessment in Neuropsychiatry (SCAN): introduction to WV's mental health community. WV Med J 1998, 94:326-328.

40. Rijnders CA, van den Berg JF, Hodiamont PP, Nienhuis FJ, Furer JW, Mulder J, Giel R: Psychometric properties of the schedules for clinical assessment in neuropsychiatry (SCAN-2.I). Soc Psychiatry Psychiatr Epidemiol 2000, 35:348-352.

4I. American Psychiatric Association: Diagnostic and Statistical Manual of Mental Disorders, Fourth edition. Washington, APA; 1994.

42. SPSS Corporation: SPSS $\mathbf{1 2 . 0}$ for Windows. 12.0th edition. Chicago,IL, SPSS Inc; 1997.

43. Jorm AF, Christensen H, Griffiths KM: The public's ability to recognize mental disorders and their beliefs about treatment: changes in Australia over 8 years. Aust N Z J Psychiatry 2006, 40:36-4I.

44. Goldney RD, Fisher LJ, Dal Grande E, Taylor AW: Changes in mental health literacy about depression: South Australia, 1998 to 2004. Med J Aust 2005, 183:134-I37.

45. Goldney RD, Fisher LJ, Wilson DH: Mental health literacy: an impediment to the optimum treatment of major depression in the community. J Affect Disord 200I, 64:277-284.

46. Fisher LI, Goldney RD: Differences in community mental health literacy in older and younger Australians. Int J Geriatr Psychiatry 2003, I 8:33-40.

47. Forsell $\mathrm{Y}$ : The pathway to meeting need for mental health services in Sweden. Psychiatr Serv 2006, 57: I14-119.

48. van Schaik DJ, Klijn AF, van Hout HP, van Marwijk HW, Beekman AT, de Haan M, van Dyck R: Patients' preferences in the treatment of depressive disorder in primary care. Gen Hosp Psychiatry 2004, 26:184-189.

49. Angermeyer MC, Matschinger H, Riedel-Heller SG: Whom to ask for help in case of a mental disorder? Preferences of the lay public. Soc Psychiatry Psychiatr Epidemiol 1999, 34:202-210.

50. Jorm AF, Mackinnon A, Christensen H, Griffiths KM: Structure of beliefs about the helpfulness of interventions for depression and schizophrenia. Results from a national survey of the Australian public. Soc Psychiatry Psychiatr Epidemiol 2005, 40:877-883.

5I. Benkert O, Graf-Morgenstern M, Hillert A, Sandmann J, Ehmig SC, Weissbecker H, Kepplinger HM, Sobota K: Public opinion on psychotropic drugs: an analysis of the factors influencing acceptance or rejection. J Nerv Ment Dis 1997, 185:151-158.
52. Jorm AF, Christensen H, Medway J, Korten AE, Jacomb PA, Rodgers $B$ : Public belief systems about the helpfulness of interventions for depression: associations with history of depression and professional help-seeking. Soc Psychiatry Psychiatr Epidemio 2000, 35:21I-219.

53. Jorm AF, Nakane $Y$, Christensen H, Yoshioka K, Griffiths KM, Wata Y: Public beliefs about treatment and outcome of mental disorders: a comparison of Australia and Japan. BMC Med 2005, 3:12.

54. Angermeyer MC, Matschinger $\mathrm{H}$ : Public beliefs about schizophrenia and depression: similarities and differences. Soc Psychiatry Psychiatr Epidemiol 2003, 38:526-534.

\section{Pre-publication history}

The pre-publication history for this paper can be accessed here:

http://www.biomedcentral.com/1471-2458/8/8/prepub
Publish with Bio Med Central and every scientist can read your work free of charge

"BioMed Central will be the most significant development for disseminating the results of biomedical research in our lifetime. "

Sir Paul Nurse, Cancer Research UK

Your research papers will be:

- available free of charge to the entire biomedical community

- peer reviewed and published immediately upon acceptance

- cited in PubMed and archived on PubMed Central

- yours - you keep the copyright
BiolMedcentral 